\title{
La ley natural como fundamentación filosófica de los derechos humanos Hermenéutica analógica y ontología
}

\author{
MAURICIO BEUCHOT \\ Universidad Nacional Autónoma de México \\ mbeuchot50@gmail.com
}

\begin{abstract}
Resumen
El presente trabajo tiene como objetivo hacer comprensible la posibilidad de una determinación ética en el universo de la racionalidad tecnológica y ofrecer puntos de referencia que permitan al hombre orientarse en un mundo cada vez más artificial.
\end{abstract}

Palabras clave: hermenéutica, ciencia moderna, racionalidad tecnológica.

\section{The natural law as the philosophical foundation of human rights Analog hermeneutics and ontology}

\begin{abstract}
The objective of this work is to make comprehensible the possibility of an ethical determination in the universe of technological rationality and to provide points of reference in order to guide the buman person in an increasingly artificial World.
\end{abstract}

Key words: hermeneutics, modern science, technological rationality.

Miembro de la Academia Mexicana de la Historia, de la Academia Mexicana de la Lengua, y de la Academia Pontificia de Santo Tomás de Aquino. Coordinador del Seminario de Hermenéutica en el Instituto de Investigaciones Filológicas de la UNAM. Es autor de más de 40 libros que abarcan temas de Filosofía medieval, Filosofía del lenguaje, Filosofía analítica, Estructuralismo y sobre todo la Hermenéutica. De los más recientes cabe mencionar: Hermenéutica analógica, símbolo y ontología (2010), La bermenéutica analógica en la historia (2010) y Retóricos de la Nueva España (2010). 


\section{Introducción}

En estas páginas, deseo mostrar que la hermenéutica puede apoyar a los derechos humanos, pero que tiene que hacerlo desde una ontología que la acompaña, ya que sin una ontología nos quedamos sin antropología filosófica o filosofía del hombre (que es una ontología de la persona), y sin ello no podemos dar a los derechos humanos un sustento suficiente. Tal fundamento es la ley natural, la cual supone una ontología y una antropología filosófica, para desde allí dar base a la ética y al derecho. Esto se da sobre todo en una hermenéutica analógica, que trata de conjuntar el lado hermenéutico con el lado ontológico. Así, pues, trataré de hacer ver que una hermenéutica analógica, con una ontología analógica, aporta las bases para una fundamentación filosófica suficiente de los derechos humanos.

Se suelen fundamentar los derechos humanos en la dignidad del hombre, que es la manera kantiana, al parecer la más aceptada. También se fundamentan en las necesidades humanas, cosa menos extendida pero que también ha logrado aceptación. Pero me parece que ambas cosas se reducen, en definitiva, a la naturaleza humana; pues, ¿de dónde surge la dignidad humana sino de la naturaleza humana?, y ¿de dónde brotan las necesidades humanas sino de la naturaleza humana misma? Sin embargo, cuando se habla de una fundamentación de los derechos humanos en la naturaleza del hombre, de inmediato se opone a ello la acusación de cometer falacia naturalista. Por eso dedicaremos un espacio a considerarla, y tratar de hacer ver cómo la hermenéutica analógica evita esa acusación, la recusa. Es una manera de recuperar la ontología para que sirva al hombre, sobre todo en esos derechos tan básicos.

\section{Hermenéutica y ontología}

En la fundamentación filosófica de los derechos humanos se ha dado la incesante pugna entre el iusnaturalismo y el iuspositivismo ${ }^{1}$. La primera corriente defiende un fundamento ontológico de los derechos humanos, el cual es la ley natural o derecho natural, mientras que la segunda lo niega, y sólo postula como base de tales derechos la positivación. Hay además posturas intermedias, como la de los derechos morales (Moral Rights), pero los iuspositivistas los ven como derechos naturales. La principal objeción que los iusnaturalistas han esgrimido

1 M. BEUCHOT: Derechos humanos, iuspositivismo y iusnaturalismo. Universidad Nacional Autónoma de México, México 1995, 25ss. 
contra el iusnaturalismo y la ley natural es la acusación de falacia naturalista que, desde Hume, pasando por Moore y llegando a la actualidad, sostiene que fundamentar los derechos humanos en una naturaleza humana, esto es, en una ley natural, es realizar un paso indebido, a saber, el del ser al deber ser.

La hermenéutica ha traído algunas aportaciones a este tema de la fundamentación filosófica de los derechos humanos. Una de ellas, me parece a mí, es la que señala Paul Ricoeur, a saber, que recusa la acusación de falacia naturalista y permite pasar del ser al deber ser, ya que pide que los derechos (y sobre todo los derechos humanos) tengan como base la interpretación del hombre, esto es, una antropología filosófica ${ }^{2}$, la cual redunda en el estudio de la naturaleza humana. Con ello se podrá ver cuál es la ley y el derecho que surgen de él, a saber, la ley natural, o el derecho natural, y se entienden los derechos humanos como derechos naturales subjetivos, según los entendía la Escuela de Salamanca, con Vitoria y Soto, y con la que estuvo vinculado Bartolomé de las Casas.

La doctrina de la ley natural es, ciertamente una doctrina perteneciente al derecho, más propiamente, la filosofía del derecho. Pero consiste precisamente en conectar el derecho con la moral, con la ética. Y para ello se tiene que hacer intervenir la antropología filosófica, pues tanto el derecho como la ética deben servir al hombre, tienen que corresponder al hombre y, para ello, comprender la naturaleza humana. Sabemos, además, que la antropología filosófica supone una ontología, incluso puede decirse que es una ontología de la persona. Así, la ontología da base a la antropología filosófica, ésta a la ética y ésta al derecho. En efecto, un derecho que no sea moral, se autorrefuta o autodestruye (como se decía en el iusnaturalismo clásico, una ley injusta no es ley). Además, la ética responde a una concepción del hombre, lo cual es propio de la antropología filosófica. Y la antropología filosófica o filosofía del hombre descansa en los principios establecidos por la ontología. Tal es la secuencia armónica de la filosofía misma.

Así, pues, la ley natural es la que surge de la misma naturaleza humana. Desde los griegos, principalmente en Aristóteles, pasando por los medievales, singularmente Santo Tomás, hasta la actualidad, la ley natural consiste en obedecer, desde el derecho, la misma estructura ontológica de la realidad, la naturaleza ${ }^{3}$. Se habló de preceptos de la ley natural que se basan en la ley común al hombre y a los animales, pero sobre todo se trataba de la naturaleza humana, en la cual se dan instintos

\footnotetext{
2 P. Ricoeur: Lo justo. Ed. Caparrós, Madrid 1999, 27-29.

3 J. FINNIS: Absolutos morales. Tradición, revisión y verdad. Ediciones Internacionales Universitarias, Barcelona 1992, 16-17.
} 
como los de los animales, pero son llevados con la égida de la razón humana. En todo caso, de la naturaleza humana misma brotan esos derechos naturales que ahora denominamos derechos humanos.

Cuando se dice que los derechos humanos surgen de las necesidades humanas, caemos en lo mismo, pues las necesidades humanas se basan en la naturaleza humana. Y cuando se dice, más kantianamente, que el fundamento de los derechos humanos es la dignidad humana - y esta fundamentación kantiana de tales derechos es hoy por hoy la más aceptada - volvemos a lo mismo: la dignidad humana se basa en la naturaleza humana, está arraigada en ella.

La ley natural, así como el derecho natural, es el fundamento de los derechos humanos para el iusnaturalismo. Algo se acerca a ello la escuela de los Moral Rights, pues, al ser derechos morales, no se quedan en derechos positivos, sino que están más allá de la positivación. Su validez no depende de que sean positivados, y con ello se les retira de ese ámbito jurídico, y pertenecen al ámbito moral, con lo cual se fundamentan -al igual que la moral- en la antropología filosófica y ésta en la ontología. No nos escapamos de la ontología al buscar la fundamentación filosófica de tan importantes derechos.

Quizá lo más importante aquí es que ha pasado el tiempo del positivismo lógico, y con ello también el del positivismo jurídico. Ya la filosofía del derecho tiende a alejarse cada vez más del iuspositivismo y, aun cuando no llega exactamente a adoptar el iusnaturalismo, se acerca a él, o por lo menos oscila entre esas posturas intermedias como la de los Moral Rights. En todo caso, asistimos a una época post-positivista, tanto en la filosofía como en el derecho.

Esto hace que se estén buscando fundamentaciones de los derechos humanos más substantivas, que van desde una postura pragmatista hasta una aceptación decidida de la ontología. En estos tiempos la ontología ha sido mal vista, pero poco a poco se asiste a lo que podríamos llamar un «giro ontológico», así como antes se habló de un «giro lingüístico» y de un «giro hermenéutico». Inclusive puede decirse que este giro hermenéutico, al menos en el caso de Ricoeur, preparó para el giro ontológico del que estamos hablando.

Sobre todo una hermenéutica analógica, que pretende evitar el rigorismo de la hermenéutica unívoca y el laxismo de la hermenéutica equívoca, acepta apoyar la recuperación de la ontología. Una ontología analógica, al igual que la hermenéutica que la acompaña. La ontología que se quiere recuperar es, precisamente, una ontología analógica como la de Aristóteles y la de Santo Tomás. En la modernidad hubo ontologías unívocas, tanto racionalistas como empiristas, todas demasiado rígidas y pretenciosas, lo que determinó su desplome y su ruina. Pero ahora, en la 
posmodernidad, proliferan las ontologías equívocas, ya se las llame débiles, de la actualidad, complejas, etc., se encuentra uno con una ambigüedad demasiado fuerte, lo que impide tener estructuras ontológicas suficientes.

Necesitamos, pues, una ontología analógica, que no tenga la pretensión rigorista de las ontologías unívocas de la modernidad, pero que tampoco se derrumbe en la desesperación disolvente de las ontologías equívocas de la posmodernidad. Una que tenga la fuerza suficiente para salir de la debilidad y la ambigüedad de las ontologías al uso, que más bien no son ontologías (si bien se las mira). Una ontología abierta, pero resistente; una ontología seria, pero abierta, es decir, no reduccionista como las del positivismo, pero tampoco irreductible, como muchas de la posmodernidad.

Es una ontología analógica, como la de Aristóteles, Tomás de Aquino y, en la actualidad, la de Ricoeur, la de Putnam y otros, que buscan una ontología que sea abierta pero más resistente que las vagarosas, como la de Vattimo, la de Rorty y la de otros. Una que todavía hable de naturalezas, de la verdad y la objetividad, y que no renuncie a toda estructuración ontológica de la realidad, pues sin ello nos quedamos con un edificio caído.

\section{El hombre y sus derechos}

Precisamente es esa ontología analógica la que nos va a permitir hablar del hombre. Una filosofía del hombre es, en su núcleo, una ontología del ser humano, con la noción clave de persona. Esta antropología filosófica (que Heidegger criticó, frente a Cassirer, supliéndola por la ontología fundamental del Dasein) nos puede ayudar a fundamentar los derechos humanos. Ya ha pasado el tiempo de la acusación de este paso como falaz, la falacia naturalista, que prohíbe pasar del ser al deber ser, del hecho al valor, de lo descriptivo a lo prescriptivo; por ello, del ser del hombre a sus derechos.

Más aún, algunos han visto que la ética y el derecho mismo se han de basar en la naturaleza humana, como Putnam y otros. De otra manera, no responderá a las necesidades y aspiraciones del hombre. Ya se ha quitado el miedo al iusnaturalismo; incluso se ha visto que, últimamente, el iuspositivismo ya no es tan radical, ni el propio iusnaturalismo, y llegan a coincidir en puntos fundamentales. Hay una

\footnotetext{
4 Cfr. M. Heidegger: Kant y el problema de la metafísica. Fondo de Cultura Económica, México 1954.
} 
aceptación de que los derechos humanos no dependen de la sola positivación, que necesitan algo más, y eso es responder a exigencias éticas o morales. Hay incluso cierto consenso en que se basan en algo ético, por lo que Javier Muguerza, Eusebio Fernández y otros los ven como Moral Rights, derechos morales, que se dan en las legislaciones del lado de los derechos fundamentales, y rebasan la mera positivación, tienen un fundamento distinto, una razón suficiente propia.

También hay un gran consenso, tras la línea de Kant, en poner como fundamento de los derechos humanos la dignidad humana. Igualmente, se han usado como fundamento de los derechos humanos las necesidades humanas. Pero ambas cosas nos remiten a la naturaleza humana y se reducen a ella: la dignidad humana se asienta en la naturaleza humana y las necesidades humanas brotan de la naturaleza humana. Ambos fundamentos recientes (dignidad humana y necesidades humanas) a la postre se reducen, me parece, al antiguo, que era la naturaleza humana.

Se ha tenido miedo al iusnaturalismo, por considerarlo definitivo y cerrado. Pero hay varios iusnaturalismos, que conviene distinguir. Aunque hablamos de iusnaturalismo, aquí deseamos sostener uno conectado con la historia, un iusnaturalismo histórico, según lo ha llamado Jesús Antonio de la Torre ${ }^{5}$. Él se inspira en el filósofo Ignacio Ellacuría, seguidor de Xavier Zubiri y asesinado en Centroamérica. Ellacuría habló de que los derechos humanos se ven usualmente como abstracciones, como ideales, sin la reflexión acerca de que hay que llevarlos a la concreción del aquí y el ahora. Hay que verificar si en el momento concreto se están dando, o si algo los está impidiendo, y qué se puede hacer para promoverlos.

Tal vez habría que renovarse, crear un poco, desarrollar una nueva teoría de esto, o tal vez cambiar de terminología, de categorías. En lugar de hablar de derecho natural, hablar de un derecho universal. No positivo, sino previo. Existe un genoma humano, y de ahí brotan necesidades que son universales; por lo tanto, hay derechos universales que atienden a ellas. Hay que crear nuevas categorías, para hacer la crítica del derecho en la actualidad desde la actualidad. Pero también me parece que lo antiguo extrañamente puede criticar a lo moderno, como lo hace el iusnaturalismo clásico (por ejemplo de la Escuela de Salamanca: Vitoria, Soto, Las Casas...) incluso con el moderno y los derechos humanos contemporáneos, que llevan demasiado individualismo y requieren un tinte más comunitario.

5 J. A. DE LA TORRE: Derechos humanos desde el iusnaturalismo histórico analógico. PorrúaUAA, México 2001, 46ss. 
En el caso de De la Torre, se trata de un iusnaturalismo histórico analógico, ya que incorpora elementos de mi hermenéutica analógica, así como elementos de la hermenéutica diatópica, usada por Boaventura de Souza Santos, iusfilósofo portugués que trabajó en Brasil. Souza aboga por un derecho más prudencial y no sólo aplicativo, es decir, invoca la interpretación, la hermenéutica. Afronta el hecho del multiculturalismo, pero no es relativista. Dice que cada cultura desarrolla topoi (o tópicos, lugares) que se pueden universalizar, al menos parcialmente, mediante el diálogo. (Serían universales no unívocos). Pide que, sin perder la universalidad, se privilegien o se apoyen los topoi. En algunos puntos habrá acuerdos, pero también habrá diferencias. En las diferencias hay que introducir el respeto. Es decir, hay límites ${ }^{6}$. Souza habla de un cosmopolitismo y un patrimonio de la humanidad, que son formas de globalizar lo que comienza siendo local ${ }^{7}$.

En cuanto a la hermenéutica analógica, busca algo parecido, con la idea de universal análogo ${ }^{8}$ (que también utiliza Enrique Dussel) ${ }^{9}$. Una hermenéutica analógica obliga a evitar la univocidad de imponer un único modo de cumplir o realizar los derechos humanos, negando todo multiculturalismo, y evita asimismo la equivocidad de relativizar tanto los derechos humanos a las culturas, que se pierda la universalidad que los caracteriza, y sin la cual dejarían de ser lo que son. Es, empero, una universalidad analógica, son universales análogos. Los derechos humanos son universales análogos, que se aplican con universalidad, pero con diferencia; ahora bien, con una diferencia limitada. Tal es la idea de la analogía, que es limitar la equivocidad (y la univocidad también, por supuesto, pero la más necesitada de límites ahora es la equivocidad).

La hermenéutica analógica, pues, rescata a los derechos humanos su fundamentación. En una naturaleza humana que se despliega en dignidad humana y necesidades humanas. Trata de incluirlas y compatibilizarlas. La misma naturaleza humana confiere al hombre una alta dignidad, y eso hace que sus necesidades participen de esta dignidad, se vuelven algo a lo que tiene derecho. «Toda necesidad engendra derecho», decían los antiguos. Y aquí se ve cómo las necesidades humanas engendran derechos para el hombre, y con tanta más dignidad cuanta es la exigencia que se tiene de atender a la dignidad humana misma, que reclama la

6 B. DE SOUSA SANTOS: Por una concepción multicultural de los derechos humanos. UNAMCIICH, México 1998, 12-18 y 24-34.

$7 \quad$ B. DE SOUSA SANTOS: La globalización del derecho. Los nuevos caminos de la regulación y la emancipación. Universidad Nacional de Colombia-ILSA, Bogotá 1999.

8 M. BEuCHOT y G. MARQuínez ARgOTE: Hermenéutica analógica y filosofía latinoamericana. Editorial El Búho, Bogotá 2005, 67.

$9 \quad$ Ibíd., 59-60. 
satisfacción de esas necesidades con dignidad, con sendos derechos. Y todo ello se reúne en la naturaleza humana, que es la que hace digno al hombre y es la que da sustento y apoyo a las necesidades que se le presentan. Una hermenéutica analógica trata de incluir todos esos lados del problema, superando la dicotomía entre necesidades y dignidad, y entre dignidad y naturaleza humana ${ }^{10}$.

Asimismo, una hermenéutica analógica trata de superar la dicotomía entre ser y deber ser, entre hecho y derecho, entre descripción y valoración. La analogía permite que un mismo discurso tenga un lado descriptivo y un lado valorativo, no están tan separados. Tienen presencia analógica o proporcional, el discurso tiene una proporción de cada uno de esos extremos. Y, en efecto, en muchos casos encontramos, por la misma hermenéutica, que un discurso, en apariencia meramente descriptivo, tiene contenidos valorativos. Ya al dar una noticia política, no podemos evitar la carga valorativa que depositamos en ella. Mucho más al contar la historia, al historiar los acontecimientos, solemos manifestar nuestra calificación moral de las acciones que estamos contando, no es un relato neutro.

De manera semejante, una hermenéutica analógica resalta la posibilidad de interpretar al ser humano a la hora de darle una ética, o un derecho, sobre todo los derechos humanos. De otro modo haríamos una ética o un derecho que no se adecue al hombre mismo, con lo cual le harán muy flaco servicio. No sólo pueden basarse en la naturaleza humana, sino que tienen que hacerlo. Ahora lo que buscábamos como posibilidad se nos convierte en exigencia, si es que deseamos en verdad responder al ser humano en lo que tiene de más propio: su dignidad, sus necesidades y sus aspiraciones.

\section{Fundamentación hermenéutico-ontológica}

Pero, precisamente, una hermenéutica analógica alcanza a fundamentar filosóficamente los derechos humanos porque los asienta en una antropología filosófica, o filosofía del hombre, la cual es, de hecho, una ontología de la persona. Es decir, la antropología filosófica es la aplicación de la ontología al ser humano, para encontrar lo que le pertenece por esencia (entre otras cosas, esos derechos tan fundamentales).

Pero, precisamente, la ontología era vista por Heidegger como hermenéutica de la facticidad. Era la hermenéutica del ser ahí, del ser del

M. BEUCHOT: Interculturalidady derechos humanos. Siglo XXI, México 2005, 18-20. 
hombre. Él rechazaba la antropología filosófica, como se lo hizo saber a Cassirer, que la cultivaba, pero vemos que suplía la antropología filosófica por su ontología fundamental del ser ahí, del hombre. Con lo cual nos remite a la ontología como hermenéutica, y volvemos a la hermenéutica como la que nos va a posibilitar una filosofía del hombre que sea adecuada.

Adecuada porque parte de la interpretación del hombre mismo, en busca de su esencia, pero no presuponiéndola de antemano, a priori, sino buscándola a posteriori, a través de la interpretación de la cultura, como pedía Paul Ricoeur. La cultura nos indica cuál es la naturaleza del hombre, la historia nos entrega su esencia, pues en los acontecimientos históricos, en las acciones del hombre, está contenida y manifestada su esencia, su naturaleza.

$\mathrm{Y}$ una de las cosas que nos indica la naturaleza del hombre es su carácter jurídico, por lo mismo que ético y político. El hombre tiene por naturaleza la capacidad de tener derechos, el derecho a tener derechos, como también se le ha llamado. Y es, asimismo, la capacidad de tener derechos que responden a la misma naturaleza del hombre, lo que denominamos derechos humanos.

De modo que los derechos humanos responden a la misma naturaleza del hombre, son lo que se ha llamado derechos naturales, subjetivos, es decir, entendidos como derechos que son del individuo. Y, aun así, entendiéndolos como derechos del individuo, y para evitar el solo individualismo, hay que darles un carácter más comunitario, una proyección más hacia la comunidad. Eso evitará su consideración egoísta o meramente individualista y les dará un sentido más orientado hacia la comunidad. Hasta el grado de admitir derechos humanos de la comunidad, derechos humanos comunitarios (por ejemplo, las culturas tienen derecho a vivir, a no ser mutiladas o dislocadas, a preservar su lengua, etc.). Cosas análogas al individuo, son derechos análogos a los del individuo. Esto nos hará más conscientes de nuestra pertenencia a la sociedad, por más libres que nos queramos pensar frente a ella.

$\mathrm{Y}$ esto es algo que resulta de una antropología filosófica elaborada con la hermenéutica, más concretamente, con una hermenéutica analógica, ya que una hermenéutica unívoca solamente verá los derechos como individuales, con ese absolutismo que ha tenido el liberalismo; pero una hermenéutica equívoca los verá relativistamente desde la comunidad, únicamente como colectivos, relativos a una comunidad, si no es que los hará desaparecer, como quiso hacerlo en algún momento el comunitarista MacIntyre, para suplirlos por las virtudes políticas ${ }^{11}$. Claro

11 A. MacINTYRE: Tras la virtud. Crítica, Barcelona 1987, $96 \mathrm{ss.}$ 
está que, si tuviéramos esas virtudes, los derechos humanos saldrían sobrando, como saldrían sobrando todos los derechos. Pero, recordemos que Platón tuvo ese ideal, en su diálogo La república, donde quiso excluir las leyes y confiar en que los hombres fueran guiados por las virtudes. Pero tuvo que escribir otro diálogo, que lleva precisamente el nombre de Las leyes, porque se dio cuenta de que los hombres no se dejaban guiar por la virtud y había que mantener la existencia de las leyes y la coerción que las acompañaba.

Con ello habremos atendido a la naturaleza del hombre, para plantear los derechos, sobre todo los derechos humanos, de acuerdo con lo que su esencia pide y exige. No podemos darnos el lujo de dejar sin fundamento derechos tan importantes. Además, esta fundamentación, que antes se reservaba al filósofo, ahora está siendo asumida, cada vez con mayor empeño, por los juristas interesados en los derechos humanos. Si no tenemos un fundamento filosófico firme para apoyarlos, no los podremos defender, porque estaríamos defendiendo algo inexistente, puros buenos deseos. Hay que darse a la tarea de fundamentarlos filosóficamente, de manera ontológica, con la ayuda de la hermenéutica, lo cual es tan importante para su defensa como el tener tribunales que los hagan valer. Poco a poco va creciendo la conciencia, no sólo entre los filósofos, sino también entre los juristas, de que todo derecho tiene detrás una filosofía del derecho, y que más vale conocerla y explicitarla, para no quedar condenados, por ignorarla, a repetir la que está al uso en la sociedad que nos toca. Tenemos que ser críticos con ella, para defender por encima de todo esos derechos humanos que marcan el alto ideal que deseamos para el hombre mismo.

Una hermenéutica analógica, pues, rescata la ley natural, como fundamento de los derechos humanos. En efecto, la hermenéutica, al exigir que la ética se construya a partir de una interpretación del hombre, va más allá de la acusación de falacia naturalista. Antes bien, muestra que siempre damos ese paso del ser al deber ser, de la descripción y la interpretación a la prescripción. Y que, si no lo hacemos, estaremos construyendo una ética y un derecho que no serán adecuados al ser humano.

\section{Conclusión}

De esta manera vemos que, en primer lugar, la hermenéutica no está divorciada de una ontología, antes la supone y se acompaña de ella. En segundo lugar, con esta ontología podemos abordar una antropología filosófica, o filosofía del hombre, ya que ésta consiste sobre todo en una 
ontología de la persona (a tal punto que Heidegger, contra Cassirer, quiso prescindir de la antropología filosófica en aras de una ontología fundamental del Dasein o ser humano). Ya con esta antropología filosófica, que nos habla de los rasgos principales de la naturaleza humana, podemos usar a esta última para la fundamentación de los derechos humanos, ya que ahora se ha desechado la idea de que esto es un paso en falso, una falacia naturalista, de pasar del ser al deber ser, como si fuera algo falaz, pues es más bien algo que hacemos continuamente, y que tenemos que hacer si queremos dar al hombre unos derechos que de verdad le correspondan y le resulten adecuados.

Por eso ha habido que examinar los diferentes iusnaturalismos, ya que son diversos. Y en la actualidad, después de muchas críticas mutuas, el iuspositivismo actual ha llegado a coincidir en varios puntos esenciales con el iusnaturalismo actual, que ya no es excesivo como el anterior, que fue el moderno, y no tanto el clásico, que fue menos pretencioso y rígido. Por eso cabe hablar de un iusnaturalismo analógico, que dé a los derechos humanos un sustento no rígido, pero suficiente. Esto nos hace ver la utilidad de la hermenéutica para el derecho, no sólo para interpretar los derechos o leyes, sino además para fundamentarlos, como se ve en este caso de los derechos humanos, que son derechos tan trascendentales.

Sumario: Introducción; 1. Hermenéutica y ontología; 2. El hombre y sus derechos; 3. Fundamentación hermenéutico-ontológica; Conclusión. 